\title{
emerald PUBLISHING
}

\section{International Journal of Organization Theory \& B€}

\section{Measuring organizational climate via psychological networks analysis}

\begin{tabular}{|r|l|}
\hline Journal: & International Journal of Organization Theory \& Behavior \\
\hline Manuscript ID & IJOTB-08-2020-0142.R2 \\
\hline Manuscript Type: & Research Paper \\
\hline Keywords: & $\begin{array}{l}\text { Organizational climate, psychological networks, thriving at work, } \\
\text { organizational commitment, remote working }\end{array}$ \\
\hline \multicolumn{2}{|l}{} \\
\hline
\end{tabular}

\section{SCHOLARONE \\ Manuscripts}

(C) 2021, Emerald Publishing Limited. This AAM is provided for your own personal use only. It may not be used for resale, reprinting, systematic distribution, emailing, or for any other commercial purpose without the permission of the publisher. 


\title{
Measuring organizational climate via psychological networks analysis
}

\begin{abstract}
Purpose - This study investigates organizational climate under the Thriving at Work perspective using a network approach. We demonstrate how organizational climate functions as a complex system and what relationships between variables from different dimensions are the most important to characterize the construct.
\end{abstract}

Design/methodology/approach - By surveying 119,266 workers from 284 companies based in Brazil, we estimated a Gaussian Graphical Model with LASSO regularization for the complete dataset and for two subsets of cases randomly drawn from the whole dataset. The walktrap algorithm was applied for community detection, and a strong model for measurement invariance was fit to test whether the organizational climate is perceived similarly across groups.

Findings - Results show that the networks estimated for all datasets are quite consistent, with a similar number of communities and items detected. The same pattern was found for the Expected Influence of each item. Measurement invariance was confirmed, showing that organizational climate is perceived similarly in the two subsets. The most important community detected whose items have higher levels of centrality was organizational commitment, followed by a community centered around macro-organizational aspects covering cultural integrity, organizational agility and responsible leadership.

Originality - To our knowledge, this is the first study that investigates organizational climate using psychological networks; it provides a better understanding of the relationships established between items from different dimensions as opposed to the common cause framework whose focus is on the investigation of dimensions separately.

Keywords: Organizational climate, psychological networks, thriving at work, organizational commitment, remote working. 
Article classification: Research paper.

\section{Introduction}

Organizational climate consists of shared perceptions the organization members have about different aspects of their workplace. Because of its complex and multifaceted nature, organizational climate is often linked to several other organizational variables such as individual and organizational performance, customer satisfaction, knowledge sharing, organizational commitment, innovative work behavior and self-efficacy, to name a few. Among the different techniques used for studying organizational climate, psychometric instruments have been arguably the most common way to analyze workers' perceptions toward various aspects of their job. The methodological rigor and statistical procedures involved in such a measurement process have warranted the development of several instruments to measure the construct and investigate its dimensionality.

By carrying out annual organizational climate research, organizations usually choose the dimensions that fit their business strategies and that may provide information on employee's satisfaction regarding different personal, team and organizational aspects (Ćulibrk et al., 2018; Mulki and Lassk, 2019). This approach is relevant because it can produce a great deal of information about the individual's satisfaction toward different organizational dimensions. Nonetheless, it does not provide further insights on how variables from different dimensions relate to one another. For instance, workers' dissatisfaction with the organization's leadership might affect the individual's sense of collaboration, which could have a negative impact on how information is shared across different departments; or the lack of resources and poor infrastructure could prevent organizational innovation and eventually hinder the organizational image. Associations like these have been studied more recently by a new field of investigation called psychological networks, also known as network analysis or network psychometrics. Psychological networks are defined as a complex 
interplay of psychological variables that offer a different conceptual interpretation of the data by explaining conditioned co-occurrences via direct relationships between variables and their neighborhood of interactions (Epskamp et al., 2018; van der Maas et al., 2006). Unlike social network analysis, which seeks to investigate relationships or interactions between individuals, psychological networks focus on interactions between variables.

The first applications of psychological networks sought to understand better how depression symptoms interact with one another and how they cluster in the way they do. Epskamp et al. (2018) demonstrated that having sleep problems may lead to loss of energy, which may trigger low self-esteem and reinforce sleep deprivation. By exploring relationships among variables measuring depression, the focus shifts from targeting individual symptoms to a more comprehensive characterization of the disorder itself in terms of its composite networks (Borsboom et al., 2019). This new theoretical and methodological approach contrasts with the common cause framework, which postulates that variance in the symptoms is causally determined by a latent variable named depression. While applied to organizational scenarios, network analysis may help understand the complex relationships among perceptions and attitudes toward different macro- and micro-organizational aspects, including organizational climate.

Backed by Graph Theory, psychological networks allow for information exchange across multiple dimensions, irrespective of what dimension an item belongs to. That said, item validity should be tested beforehand so that only useful items are included in the network analysis. Also, to control for spurious correlations, only constructs or dimensions proved to be theoretically and empirically associated should be part of the same network.

This study seeks to address the emerging but limited research on psychological networks in organizational behavior by estimating a network of mutually reinforcing variables measuring organizational climate. As such, the foci of this paper are threefold. First, 
it introduces the application of psychological networks (Epskamp et al., 2018) to the investigation of the relationships established between items and dimensions of organizational climate, something that has not been attempted before. Second, it identifies the most central items for the organizational climate network considering mutual and conditional interactions among different variables and dimensions. Finally, it shows how organizational climate functions as a complex system and what relationships are the most important to characterize the construct.

\section{Organizational climate and Thriving at Work}

Organizational climate is usually defined as a multidimensional construct since it covers the worker's attitudes toward different elements of their organization, such as leadership, benefits, team, performance management, strategic planning, and so forth. Therefore, the multidimensionality of organizational climate is related to the extent to which the construct embraces the complexity and diversity of factors that are subject to the individual's perception. Based on this perspective, various definitions of organizational climate have been developed focusing on how individuals perceive an organizational environment and respond to it (Moran and Volkwein, 1992; Tustin, 1993; Patterson et al., 2005). Accordingly, given a large amount of research published on its conceptualization, this study does not intend to cover the vast array of definitions of organizational climate. For a more in-depth discussion on its definitions and variants, please refer to Glick (1985), Schneider et al. (2011), Lawthom et al. (2005) and Barbera (2014).

For this investigation, we adopted Schneider, Ehrhart, and Macey's (2011) definition, derived from previous studies (Ostroff et al. 2003, Schneider \& Reichers 1983, Schneider et al. 2011) to describe organizational climate as "the shared perceptions of and the meaning attached to the policies, practices, and procedures employees experience and the behaviors 
they observe getting rewarded and that are supported and expected" (p. 362). Moreover, we relate the concept of organizational climate to Thriving at Work, which focuses on elements of organizational climate that can create a positive and supportive workplace culture and contribute positively to the employee's mental health.

According to Spreitzer et al. (2005), Thriving at Work is a positive attitude that leads to the acquisition of knowledge (learning) and is conducive to positive emotions and psychological states (vitality); it has been empirically linked to job performance, work engagement, organizational support health, leader effectiveness and career satisfaction (Kleine et al., 2019; Porath et al., 2012). Coetzee (2019) considers thriving at work an important construct in Industry 4.0 because it relates to organizational climate conditions of psychological safety.

Although Thriving at Work is not a theory of organizational climate, it encompasses different workplace characteristics that directly impact the employee experience (e.g., wellbeing, organizational support, inclusive workplace, diversity training) which not coincidentally relates to the dimensions of organizational climate. Additionally, Thriving at Work is concerned with elements of organizational climate that can be improved to better support employees, including those that are preventing employees from being successful at work.

The Thriving at Work approach related to organizational climate and adopted in this study bears similarities to Kahn's theory of employee engagement (1990) as it involves the worker's experiences of psychological states that can drive different levels of engagement. Bakker, Schaufeli, Leiter and Taris (2008) also emphasized the theoretical similarities between these constructs. However, Abid et al (2018) point out that, whereas "engagement determines the level to which employees are keen to utilize their personal resources at work (Kahn, 1990), thriving identifies the degree to which individuals feel that their work gives 
them personal growth that is contingent upon creation of resources" (p.4). Despite the strong correlation found between thriving at work and employee engagement $(\mathrm{r}=0.64)$, the metaanalysis conducted by Kleine et al (2019) to explore the relationship between these constructs showed that "thriving exhibits small, albeit incremental predictive validity above and beyond positive affect and work engagement, for task performance, job satisfaction, subjective health, and burnout" (p.973).

Besides these fundamental differences between thriving and engagement, the Thriving at Work approach related to organizational climate adopted in this study differs from Kahn's theory for suggesting the inclusion of dimensions and descriptors that go beyond the scope of Kahn's theory (e.g., organizational agility, thriving individuals and compelling careers). The eight dimensions and corresponding descriptors are presented in Table 1.

\section{[Insert Table 1 Here]}

Unlike the traditional studies on organizational climate, this investigation does not intend to explore the construct multidimensionality under a common cause frameworkapproach. Instead, it introduces the use of network analysis to gain a broader understanding of how organizational climate variables interact and form patterns hardly identified by mainstream methods used in organizational behavior. We provide an overview of psychological networks and the limitations related to a common cause framework approach-in the Supplementary Materials.

\section{Method}

Participants 
The data were collected by a human resources (HR) consulting firm specializing in organizational climate research for companies worldwide. After collating the results from years 2018 and 2019, this study surveyed 119,266 workers from 284 companies from different sectors and based in Brazil, some of which are among the largest companies in the country. The majority of the respondents were male $(65.2 \%)$, with $46 \%$ of the respondents aged between 21 and 30 (52.4\%). Concerning their length of employment, $41.1 \%$ have worked in their organizations for up to three years, followed by workers whose tenure is between three and six years $(21.5 \%)$, six and 11 years (19.8\%) and more than 11 years (17.5\%). The vast majority of the respondents are in non-managerial positions $(86.5 \%)$. The two most prevalent job functions are Operations (23.9\%) and Manufacturing (18.3\%), followed by Sales (9.51\%) and Customer Service (7.38\%). Companies from different sectors account for the remainder of the participants.

\section{Instruments}

The HR consulting firm developed the instrument used for this investigation to cover different organizational aspects that connect organizational climate to the construct Thriving at Work (Spreitzer et al., 2005). Forty-three items measuring eight dimensions were validated using a sample of 1,350 respondents drawn from Amazon MTurk. Exploratory Factor Analysis (EFA) confirmed that the hypothesized latent factors were the best fit to the data, with all dimensions having internal consistency (Cronbach's alpha) above 0.70 .

All items were created to reflect positive attitudes toward the various elements under assessment, with no reverse-scored items being used. Also, they were endorsed on a fivepoint Likert scale, ranging from 1 (totally disagree) to 5 (totally agree).

Sociodemographic variables were used to study personal and professional characteristics further. The actual items used for this investigation will not be shown to comply with copyright policies, but the idea (descriptors) underlying them was presented in Table 1. 
To investigate the instrument's psychometric properties using the current sample, tests on construct validity were carried out before estimating the psychological networks, as described below.

\section{Data Collection}

Participants were invited to collaborate in the research through the company's corporate email, whose research link was redirected to the consulting company's website for the sake of compliance with confidentiality and data protection policies. An Informed Consent Statement was initially introduced to let the participants know the ethical aspects involved in this investigation, as well as the confidentiality concerning the processing and storing of the data provided. To protect the individual's privacy and confidentiality, the data was stored as non-personally identifiable information (non-PII), a procedure that does not permit the tracing or identification of an individual directly or indirectly.

\section{Data Analysis}

The data analysis was carried out in three stages.

- Construct validity

A Unidimensional Item Response Theory (UIRT) model called Graded Response Model (GRM by Muraki and Carlson, 1995) was tested to investigate whether the items belonged to their independently developed dimensions. The advantage of using UIRT models is that they are based on the individual's response patterns rather than on the correlational structure of the multivariate latent response distribution (Wirth and Edwards, 2007). Accordingly, given that the items are typically strongly correlated with their respective dimensions, we selected items that met two criteria: a) factor loadings $\geq 0.5$ and b) item discrimination $\geq 0.80$ (De Ayala, 2013). Then, based on a Classical Test Theory approach, 
we computed the corrected item-total correlation (ritc), whose values should be greater than or equal to 0.3 , and the internal consistency (Cronbach's alpha) for each scale, whose values are expected to be greater than or equal to 0.70 .

\section{- Estimation of psychological networks}

To test estimate the organizational climate network and test the replicability of this study, we used the holdout cross-validation so that $50 \%$ of the cases from the complete dataset were randomly assigned to a training dataset and the $50 \%$ remaining allocated to a testing dataset. Thus, three separate networks were estimated with 59,633 cases each and finally, with the complete dataset. A high-performance computer was used to estimate the Gaussian Graphical Model (GGM) with LASSO regularization. Since LASSO estimation penalizes near-zero edges, the interpretation of the regularized partial correlations cannot be made in the same way as in traditional correlation coefficients by creating thresholds based on their absolute values. In other words, the most significant edges or pairwise comparisons are those with stronger associations while compared against the remaining model edge coefficients.

In addition to estimating the psychological network, we calculated the Expected Influence by taking the sum of all positive and negative edge weights a node is directly connected to (Robinaugh et al., 2016). Simply put, variables with stronger associations with other variables are more central in the network and therefore more representative of the overall construct. Finally, the Fruchterman-Reingold algorithm was used to make the network visually more simple to interpret.

When networks are made up of a few nodes and edges, their interpretation tends to be more straightforward. However, for complex systems where many variables and associations make them hard to visualise and therefore understood, further analysis aimed at community 
detection may help identify clusters or groups of nodes most highly connected. Overall, community detection algorithms seek to select clusters of variables with a significant number of edges among themselves and a few edges with nodes from other communities (Briganti et al., 2018; Hoffman et al., 2016). In an analogy between psychological networks and principal component analysis, clustered nodes could be interpreted as components or as enclosed variables that can share information in a sensible way (Constantini et al., 2015; Dalege et al., 2017), though the applications of these two techniques in psychological research are not interchangeable.

For the identification of communities, we applied the walktrap algorithm (Pons and Latapy, 2005), which is one of the most reliable and computationally efficient algorithms for the identification of more extensive networks $(\mathrm{N}>1000)$ as it provides better accuracies and smaller standard deviations (Yang et al., 2016). The walktrap approach to community detection is very intuitive as it starts with random walks on a network to detect the structural similarity between nodes and between communities. These random walks tend to get "trapped" into densely associated parts of the network, generating communities from selecting groups of nodes more strongly related to one another but with weak associations with other nodes (Pons and Latapy, 2005).

\section{- Measurement invariance}

Finally, a strong model for measurement invariance was fit to test whether organizational climate is perceived similarly across the training and testing groups. In the strong invariance model, both loadings and intercepts are equal across the groups, allowing them to compare their parameters directly.

\section{Results}


We organized the findings of this research into three parts. First, we tested the psychometric properties of the organizational climate instrument to ensure the construct validity of the items to be used in the network analysis. Second, we estimated two separate networks using the training and testing datasets to check whether the relationship patterns among items are similar across groups. We applied the walktrap algorithm to detect communities and gain further insights into the relationships among items. We then calculated the Expected Influence of each item to select those that are most likely to contribute to the whole system. Finally, we computed goodness-of-fit measures to estimate a strong invariance model in order to ensure the study's replicability.

\section{Construct Validity}

To investigate the psychometric properties of the organizational climate instrument, we applied techniques from both Classical Test Theory and Item Response Theory. As shown in Table 2, the dimension average scores are strongly correlated, and internal consistency reliability is above 0.70 for all dimensions.

\section{[Insert Table 2 Here]}

Since the items were refined after the first scale validation study, we expected that they would also have acceptable psychometric properties using the current sample, as shown in Table 3. Accordingly, since the items and dimensions were found to have good psychometric properties, no items were excluded, and the final version of the instrument used for the estimation of the psychological networks was comprised of 43 items total. 


\title{
[Insert Table 3 Here]
}

\section{Estimation of psychological networks}

The networks estimated for the training, testing and complete datasets are shown in Figures 1, 2 and 3, respectively. We used the Fruchterman-Reingold algorithm to facilitate the visualization of the nodes as it does not allow them to overlap and edges have approximately the same length. Compared to one other, all networks show very similar patterns of association among nodes, with items clustered together into smaller sets more densely connected, which suggests the presence of communities. Hence, given the large number of items in the network and the difficulty to highlight the most important relationships, the interpretation of the networks was carried out from the detection of the community structure and the nodes' Expected Influence.

\author{
[Insert Figure 1 Here] \\ [Insert Figure 2 Here] \\ [Insert Figure 3 Here]
}

As can be visualized in the networks above, the interpretation of complex networks is not straightforward due to a large number of associations among the nodes and the difficulty to visualize patterns of interactions. Furthermore, the studies in psychological networks have primarily focused, so far, on improving the technique rather than creating guidelines for their interpretation. Thus, we decided to combine the investigation of the communities with the 
identification of the most central and influential items in the network to make sense of the results. As the Expected Influence is measured as z-scores, we selected the most central items above +1 (positive influence) and below -1 (negative influence). Figure 5 shows the Expected Influence for all items in both training and testing datasets. As illustrated, the position of each item across the scale is very consistent between the datasets, which is a point in favor of data replicability.

\section{[Insert Figure 4 Here]}

By applying the walktrap community detection algorithm, we noticed that the same communities were identified in both training and testing datasets. Figure 5 shows that six separate communities were detected. At the top of the figure, a dense community encompasses items from three dimensions - Cultural Integrity, Organizational Agility and Responsible Leadership. These dimensions involve macro-organizational aspects perceived by the workers as essential to promoting a safe environment, such as having a senior leadership able to make sound decisions and quickly respond to internal and external demands. The item that has the most positive influence in the community concerns the organizational support to develop new and innovative ideas (Q09_D2). This item has its highest correlation with Q06_D2 ( $\mathrm{r}=0.18)$, which also belongs to the same community and indicates how important it is for an organization to experiment with new technologies more often.

Despite the positive correlation between the two items aforementioned, Q06_D2 is the most negatively influential node from this community, suggesting that workers acknowledge that organizations should be more innovative but have failed to put such principles into practice. In addition to the component of innovation that pervades the first 
community, two other characteristics have significant, albeit equally negative values of Expected Influence. The first one regards the importance of working in a place free of harassment and discrimination (Q02_D1), which has its strongest correlation $(\mathrm{r}=0.14)$ with the idea that an organization should foster a climate of trust among employees (Q01_D1). Moreover, Q16_D3, which highlights that senior leaders should encourage information sharing, regardless of those being good or bad news, is the third most negatively influential item in this community. Q16_D3 correlates more strongly with the two other items that are part of this community and also measure Responsible Leadership. The strongest correlation occurred with item Q15_D3 ( $\mathrm{r}=0.20)$, which states that the senior leadership is responsible for making sound decisions regarding the direction of the business (Q15_D3), followed by the positive association with item Q16_D3, whose content relates to the extent to which the company balances long-term objectives and short-term achievements.

The second community identified includes all items from the dimension Compelling Careers and two items from Thriving Individuals. The different aspects involved in these dimensions ultimately relate to the idea that organizations should be providers of learning opportunities and career development, and also be able to unleash the employee's full potential. Among the most influential items from this community, three of them have a positive Expected Influence, with no items contributing negatively. The most central item was Q35_D7, which emphasizes the importance of having workers energized at work, followed by two items focusing on the opportunities offered to achieve career goals (Q32_D6) and investments made by the organization in career development (Q33_D6). The highest correlation $(\mathrm{r}=0.26)$ was between items Q35_D7 and Q31_D6, showing that feeling energized at work is coupled with the perception that working is a source of personal accomplishment. The item Q35_D7 is also more strongly correlated with two other items of the same dimension: item Q37_D7 ( $\mathrm{r}=0.16)$, addressing how much employees feel 
empowered to influence the way they do things at work, and Q36_D7 ( $r=0.16)$, which states the potential of an organization to tap into the full potential of its employees.

The third community gathers items from a single dimension called Equitable Rewards, which describes the level of employee's satisfaction toward different elements ranging from fair compensation to recognition to performance appraisal. The item Q27_D5, which conveys the idea that employees should be recognized for their efforts to achieve their goals and objectives, was the most influential within the community. Its highest correlations occurred with two other ideas from the same dimension: Q26_D5 (r=0.29), which outlines the relevance of having a reward system in line with the individual performance, and Q25_D5 ( $\mathrm{r}=0.28)$, which states that working for the organization can help workers achieve their financial goals.

The fourth community involves items primarily measured at the individual level, combining elements from the dimensions Engagement, Thriving Individuals and Healthy Work Environment. Given the number of items with high Expected Influence for the whole of the network, we can consider this community as the most representative of organizational climate. The most central item in the network is Q40_D8, which describes whether employees are keen on recommending their company as a great place to work. This item has been traditionally used in organizational climate studies since 2003 when Fred Reichheld developed the employee Net Promoter Score (eNPS), a single item that asks employees how likely they are to recommend their organization to their family and friends. This item is also related to traditional definitions of organizational commitment, or rather affective commitment. O'Reilly and Chatman (1986) described that organizational commitment encompasses feelings of pride and desire for affiliation, whereas Allen and Meyer (1990) consider that committed workers are those who are loyal, have a sense of belonging to and feel valued as members of their organizations. 
The item Q40_D8 is more strongly correlated with two other items measuring organizational commitment, Q41_D8 $(\mathrm{r}=0.44)$, which outlines how proud employees are to work for their company, and Q42_D8 ( $\mathrm{r}=0.11)$, in which individuals are asked whether they would choose to stay at their company if they were offered the same salary and benefits. These two items are also among the most central items in the network; however, whereas Q41_D8 has a positive Expected Influence, Q42_D8 lies on the negative side, showing that workers are potentially unhappy with the salary and benefits offered by their organizations. Two other items from this community are also highly influential. Whereas Q21_D4, which states how much employees fit in well with their organizations, have a positive influence, Q38_D8, which underscores how able employees are to cope with their job demands, was placed on the negative side. This reinforces the idea that workers consider organizational commitment the most positive and central aspect of organizational climate. Still, other elements connected to organizational commitment are more likely to influence the overall perception of climate negatively.

The fifth community comprises items measuring Healthy Work Environment, including the most negatively influential item in the network-Q18_D4. This item concerns the extent to which organizations have provided workers with the flexibility they need to be effective and productive (e.g., the ability to work from home, flexible work schedules, parttime options). In fact, remote working was considered in both training and testing datasets as the most critical aspect likely to influence organizational climate. However, its negative influence implies that organizations are failing to implement it. That said, as companies permanently shift working patterns to embrace remote working due to the COVID-19 pandemic, the Expected Influence of this item is likely to flip direction towards becoming more central, but on the positive side. This also suggests that working from home might 
positively impact other elements of organizational climate such as individual and organizational performance, organizational agility, and organizational climate, among others.

The final community detected is comprised of three items that emphasize Responsible Leadership - Q12_D3, Q13_D3, Q14_D3. All items focus on what degree the workers' immediate superior has been supportive of ideas, treats employees with respect and dignity, and provides feedback that helps to improve their performance. Even though none of these items is among the most influential ones, item Q13_D3, which describes the importance of having a line manager supportive of ideas and opinions, nears +1 and has a correlation of 0.19 with both items Q12_D3 and Q14_D3. It is noteworthy that all these three items address characteristics of transformational leadership; the more workers realize that their superiors are concerned with their opinions, performance and wellbeing, the more they get motivated to give their best (Han et al., 2016; Hetland et al., 2018), which has a direct impact on organizational climate.

[Insert Figure 5 Here]

\section{Measurement Invariance}

The measurement invariance was the last procedure to test whether the items measuring organizational climate function similarly for the training and testing datasets. If so, we can state that the scores produced by each group can be directly compared based on the same latent trait, i.e. organizational climate. Moreover, demonstrating measurement invariance may provide a piece of supporting evidence that the results obtained in the training dataset did not happen by chance since similar findings were also observed in the testing 
dataset. This increases the chances of replication in other samples and, therefore, the external validity of this study.

To test the measurement invariance, we opted for the strong invariance model rather than the configural invariance and weak invariance models since constraining both loadings and intercepts to be equal across datasets is a more stringent approach. The results showed that all the fit indices improved in the strong variance model as the CFI is 0.94 , the GFI is 0.98 and the RMSEA is 0.04 . These findings, alongside those produced above, corroborate this study's external validity, though its replication in different cultures and contexts is highly recommended.

\section{Discussion}

This study investigates organizational climate as a complex system by applying network analysis to a deeper understanding of the different relationships established among its components. Unlike the factor analytic approach - the mainstream research on organizational climate that seeks to identify separate dimensions for construct measurement , this investigation provides a new framework for its interpretation based on a dynamic model able to account for more complex patterns of associations. The use of psychological networks has proved advantageous in different settings whereby there are many items involved in measurement and when the type of research is mainly exploratory or comparative. For exploratory studies, just as the current investigation, cross-sectional datasets are more typically utilized, whereas for comparative studies, longitudinal data is more likely to be used for network estimation, either between- or within-subjects. For more information on how these different types of networks can be applied, refer to Constantini et al. (2019). 
When it comes to measuring work-related constructs, there is a dearth of research covering the application of psychological networks to the field of organizational behavior. Also, besides the limited number of studies conducted to date, the way psychological networks should be interpreted is not sufficiently clear since no guidelines have been introduced thus far. To overcome this limitation, we proposed in this study a combined approach involving centrality measure (Expected Influence) and community detection (walktrap algorithm) - two distinct techniques that allowed us to identify the most relevant nodes in the network and then determine what associations are more strongly formed with other items. From this combination, we learned that organizational commitment (Engagement dimension) was the most central element whose items from different dimensions are directly related to. This result places organizational commitment as an independent dimension of organizational climate and shows how likely it is to influence the worker's perceptions and attitudes toward other dimensions of organizational climate such as well-being and performance.

The association between organizational climate and organizational commitment was explained by Grant (2002), who pointed out that affective and normative commitment correlates positively with different dimensions of organizational climate such as rewards, conflict, warmth and support, approved practices, structure and ethical practices. However, no significant correlations were observed while comparing continuance commitment and organizational climate. The positive association between climate and commitment has also been reported in other studies (Bahrami et al., 2016; Berberoglu, 2018; McMurray et al., 2004).

As the measure of organizational climate employed in the current study was designed having the principles of Thriving at Work as its theoretical underpinnings, the encouragement of positive relationships in the workplace and the opportunities to grow can enhance the 
employee's intention to stay and commitment to their organization (Wild, 2019). Moreover, it can positively influence other elements such as relatedness and support, which, in turn, can stimulate feelings of belonging and organizational identification and, ultimately, contribute to their sense of purpose and meaning through work (Madden et al., 2015). These different terms such as involvement, identification and feeling of belonging have long been used interchangeably to express organizational commitment (Brown, 1969; Lee, 1971; Mowday et al., 1979; Riketta, 2005; Harris and Cameron, 2005; Lodahl and Kejner, 1965; Morrow, 1983) and show a direct and fundamental connection between the positive aspects that compose thriving at work and organizational commitment.

\section{Limitations and future research}

This study contributes to advance knowledge on how to interpret organizational climate as a complex system by introducing a new technique to the field of organizational behavior - psychological networks. Notwithstanding, a few limitations, which are also opportunities for future research, should be considered. First of all, studies in the field have attested to the possibility of investigating the phenomenon from four (Campbell et al., 1970) to over 80 dimensions (Koys and DeCottis, 1991). As a result, since several dimensions have been produced to investigate organizational climate, there is no consensus on the quality and number of dimensions that should be considered to measure such a vast and multifaceted construct. Built on the Thriving at Work perspective, eight dimensions were devised to cover a wide range of characteristics that distinguish organizational climate, including those related to Industry 4.0 (Coetzee, 2019). However, one may argue that a few dimensions, namely social responsibility, diversity and inclusion, or even more items describing work-life balance, could expand the depth and breadth of the instrument and potentially trigger new 
associations that might eventually impose a new logic to the comprehension of climate as a system. Future studies combining the dimensions investigated in this study with other dimensions are therefore highly recommended for an even more comprehensive investigation.

The second limitation concerns the design of the current research. As this study is exploratory rather than confirmatory, no hypotheses were tested to investigate organizational climate. Accordingly, as an undirected network was modeled among the items, it is not possible to identify the edges' direction. Nevertheless, based on the results of this investigation, future studies can be conducted to explore further some of the relationships encountered between variables and dimensions. Confirmatory studies with the application of directed networks could also be carried out to propose complex models that are hard to test using traditional moderation/mediation studies.

The lack of guidelines for interpreting a psychological network alongside the plethora of models and techniques that can be employed to design a network adds complexity to its application among researchers and practitioners, which can also be regarded as an important limitation. Different model configurations and choice of alternative centrality measures may lead to different results and hinder the prospect of a parsimonious and unambiguous model.

Finally, since the datasets used for this investigation date back to 2018 and 2019, changes in the shared perception of organizational climate are likely to occur after the COVID -19 pandemic. As discussed above, the attitudes toward the level of flexibility provided by organizations were hitherto quite negative, but with the compulsory, growing adoption of remote working, the centrality of such a crucial aspect can see a step change toward becoming more positively oriented. As such, a time series analysis comparing the data before and after the COVID-19 pandemic and in tandem with psychological networks could 
provide significant insights into the ontological debate regarding the concept and dimensionality of organizational climate in the coming years.

\section{Conclusions}

Organizational climate is one of the most dynamic and largely explored constructs in organizational behavior as it encompasses many variables and interactions among them. The mainstream perspective used to investigate its dimensionality is based on a factor analytic approach, which considers climate as a construct comprised of multiple dimensions, each contributing an important part of the whole construct. Despite its relevance to developing and validating psychometric instruments, the factor analytic approach is limited in modelling complex relationships among variables and dimensions. The application of psychological networks to the field of organizational behavior can help overcome this limitation and provide further insights into the investigation of constructs as complex systems.

Our research findings show that organizational commitment is the principal dimension more likely to influence other elements of organizational climate. Macroorganizational aspects relating to integrity, agility and leadership are also in prominent positions regarding climate as a whole, followed by the perception that organizations should invest in career development and equitable rewards. These findings imply that any intervention or development of policies to create healthy organizations under the perspective of Thriving at Work should start by focusing on increasing the employee's feeling of belonging and identification with their organization, which has also been considered as an essential element to promote their performance, retention and wellbeing in previous studies.

Besides its contributions to the organizational behaviour literature, practitioners would greatly benefit from using psychological networks to investigate organizational climate. Their implementation allows HR departments to identify which attributes are most 
central within the organizational context and what relationships formed between variables are most likely to impact the employees' perceptions toward different factors that constitute the organizational climate. At the macro-level, psychological networks can help organizations $\underline{\text { shape strategies and change processes focused on critical relations and key indicators }}$ identified.

\section{ACKNOWLEDGEMENTS}

We acknowledge the VIPER high-performance computing facility of the University of Hull and its support team.

\section{References}

Abid, G., Sajjad, I., Elahi, N. S., Farooqi, S., \& Nisar, A. (2018). The influence of prosocial motivation and civility on work engagement: The mediating role of thriving at work. Cogent Business \& Management, Vol. 5 No. 1, pp. 1-19. doi: $10.1080 / 23311975.2018 .1493712$

Allen, N.J. and Meyer, J.P. (1990), “The measurement and antecedents of affective, continuance and normative commitment to the organization". Journal of Occupational Psychology, Vol. 63 No. 1, pp. 1-18. doi: 10.1111/j.20448325.1990.tb00506.x

Bahrami, M.A., Barati, O., Ghoroghchian, M.S., Montazer-Alfaraj, R. and Ezzatabadi, M.R. (2016), "Role of organizational climate in organizational commitment: The case of teaching hospitals". Osong Public Health and Research Perspectives, Vol. 7 No. 2 , pp. 96-100. doi: 10.1016/j.phrp.2015.11.009 
Bakker, A. B., Schaufeli, W. B., Leiter, M. P., \& Taris, T. W. (2008). Work engagement: An emerging concept in occupational health psychology. Work \& Stress, Vol. 22 No. 3, pp. 187-200. doi:10.1080/02678370802393649

Barbera, K.M. (2014), The Oxford handbook of organizational climate and culture. Oxford University Press.

Borsboom, D. (2008), "Psychometric perspectives on diagnostic systems". Journal of Clinical Psychology, Vol. 64 No. 9, pp. 1089-1108. doi: 10.1002/jclp.20503

Borsboom, D., Cramer, A.O. and Kalis, A. (2019), "Brain disorders? Not really: Why network structures block reductionism in psychopathology research". Behavioral and Brain Sciences, Vol. 42. No. 2, pp. 1-63. doi: 10.1017/S0140525X17002266

Briganti, G., Kempenaers, C., Braun, S., Fried, E.I. and Linkowski, P. (2018), "Network analysis of empathy items from the interpersonal reactivity index in 1973 young adults”. Psychiatry Research, Vol. 265, pp. 87-92. doi:

10.1016/j.psychres.2018.03.082

Brown, M.E. (1969), “Identification and some conditions of organizational involvement”. Administrative Science Quarterly, Vol. 14 No. 3, pp. 346-355. doi: 10.2307/2391129

Campbell, J.J., Dunnette, M.D., Lawler, E.E. and Weick, K.E. (1970), Managerial behavior, performance, and effectiveness. McGraw-Hill.

Chen, J. and Chen, Z. (2008), "Extended Bayesian information criteria for model selection with large model spaces". Biometrika, Vol. 95 No. 3, pp. 759-771. doi: 10.1093/biomet/asn034

Coetzee, M. (2019), “Organisational Climate Conditions of Psychological Safety as Thriving Mechanism in Digital Workspaces”. Coetzee, M (Ed.). Thriving in Digital Workspaces, Springer, Cham, pp. 311-327. doi: 10.1007/978-3-030-24463-7_16 Constantini, G., Epskamp, S., Borsboom, D., Perugini, M., Mõttus, R., Waldorp, L.J. and 
Cramer, A.O.J. (2015), "State of the aRt personality research: A tutorial on network analysis of personality data in R". Journal of Research in Personality, Vol. 54, pp. 13-29. doi: 10.1016/j.jrp.2014.07.003

Costantini, G., Richetin, J., Preti, E., Casini, E., Epskamp, S. and Perugini, M. (2019), "Stability and variability of personality networks. A tutorial on recent developments in network psychometrics". Personality and Individual Differences, Vol. 136, pp. 6878. doi: 10.1016/j.paid.2017.06.011

Ćulibrk, J., Delić, M., Mitrović, S. and Ćulibrk, D. (2018), “Job satisfaction, organizational commitment and job involvement: The mediating role of job involvement". Frontiers in Psychology, Vol. 9, pp. 1-12. doi: 10.3389/fpsyg.2018.00132

Dalege, J., Borsboom, D., van Harreveld, F. and van der Maas, H.L.J. (2017), "Network Analysis on Attitudes: A Brief Tutorial”. Social Psychological and Personality Science, Vol. 8 No. 5, pp. 528-537. doi: 10.1177/1948550617709827

Datta, P. (2012), "An applied organizational rewards distribution system", Management Decision, Vol. 50 No. 3, pp. 479-501. doi: 10.1108/00251741211216241

De Ayala, R.J. (2013), The theory and practice of item response theory. Guilford Publications.

Epskamp, S., Borsboom, D. and Fried, E.I. (2018), “Estimating psychological networks and their accuracy: A tutorial paper". Behavior Research Methods, Vol. 50 No. 1, pp. 195212. doi: $10.3758 / \mathrm{s} 13428-017-0862-1$

Epskamp, S., Rhemtulla, M. and Borsboom, D. (2017), “Generalized network psychometrics: combining network and latent variable models". Psychometrika, Vol. 82 No. 4, pp. 904-927. doi: 10.1007/s11336-017-9557-x

Glick, W.H. (1985), “Conceptualizing and measuring organizational and psychological climate: Pitfalls in multilevel research". Academy of Management Review, Vol. 10 
No. 3, pp. 601-616. doi: 10.5465/amr.1985.4279045

Grant, W.S. (2002), Organizational Climate and Commitment: A Case Study of an Urban Nonprofit Organization. Doctor of Philosophy ( $\mathrm{PhD})$, dissertation, Old Dominion University. doi: 10.25777/dbpy-ew19

Han, S.H., Seo, G., Yoon, S.W. and Yoon, D.Y. (2016), “Transformational leadership and knowledge sharing". Journal of Workplace Learning, Vol. 28 No. 3, pp. 130-149. doi: 10.1108/JWL-09-2015-0066

Harris, G.E. and Cameron, J.E. (2005), “Multiple Dimensions of Organizational Identification and Commitment as Predictors of Turnover Intentions and Psychological Well-Being”. Canadian Journal of Behavioural Science/Revue canadienne des sciences du comportement, Vol. 37 No. 3, p.159. doi: $10.1037 / \mathrm{h} 0087253$

Hetland, J., Hetland, H., Bakker, A.B. and Demerouti, E. (2018), "Daily transformational leadership and employee job crafting: The role of promotion focus”. European Management Journal, Vol. 36 No. 6, pp. 746-756. doi: 10.1016/j.emj.2018.01.002 Hoffman, M., Steinley, D., Gates, K. M., Prinstein, M. J. and Brusco, M. J. (2018), "Detecting Clusters/Communities in Social Networks". Multivariate Behavioral Research, Vol. 53 No. 1, pp. 57-73. doi: 10.1080/00273171.2017.1391682

Kahn, W.A. (1990). Psychological conditions of personal engagement and disengagement at work. Academy of Management Journal, Vol. 33, pp. 692-724. doi: https://doi.org/10.5465/256287

Karantzas, G.C., McCabe, M.P., Mellor, D., Von Treuer, K., Davison, T.E., O’Connor, D., Haselden, R. and Konis, A. (2016), “Organizational climate and self-efficacy as predictors of staff strain in caring for dementia residents: A mediation model”. Archives of Gerontology and Geriatrics, Vol. 66, pp. 89-94. doi: 
10.1016/j.archger.2016.05.006

Kleine, A.K., Rudolph, C.W. and Zacher, H. (2019), “Thriving at work: A meta-analysis”. Journal of Organizational Behavior, Vol. 40 No. 9-10, pp. 973-999. doi: 10.1002/job.2375

Koys, D.J. and DeCotiis, T.A. (1991), "Inductive measures of psychological climate". Human Relations, Vol. 44 No. 3, pp. 265-285. doi: $10.1177 \% 2 \mathrm{~F} 001872679104400304$

Lapan, S. D., Quartaroli, M. T., \& Riemer, F. J. (2012). Qualitative research: An introduction to methods and designs. Jossey-Bass/Wiley.

Lawthom, R., Patterson, M.G., West, M.A., Staniforth, D. and Maitlis, S. (2005), "Organizational climate: A multi-level analysis". British Academy of Management, Conference, Sheffield.

Lee, S.M. (1971), “An empirical analysis of organizational identification”. Academy of Management Journal, Vol. 14, pp. 213-226. doi: 10.5465/255308

Lodahl, T.M. and Kejnar, M. (1965), “The definition and measurement of job involvement”. Journal of Applied Psychology, Vol. 49 No. 1, p.24. doi: 10.1037/h0021692

Maak, T., \& Pless, N. M. (2006). Responsible leadership in a stakeholder society-a relational perspective. Journal of business ethics, 66(1), 99-115. doi: 10.1007/s10551-006-9047Z

Madden, L., Mathias, B.D. and Madden, T.M. (2015), “In good company: The impact of perceived organizational support and positive relationships at work on turnover intentions". Management Research Review, Vol. 38 No. 3, pp. 242-263. doi: 10.1108/MRR-09-2013-0228

Marsman, M., Borsboom, D., Kruis, J., Epskamp, S., van Bork, R., Waldorp, L.J., Maas, H. L.J. van der and Maris, G. (2018), “An Introduction to Network Psychometrics: 
Relating Ising Network Models to Item Response Theory Models”. Multivariate Behavioral Research, Vol. 53 No. 1, pp. 15-35. doi: 10.1080/00273171.2017.1379379

McMurray, A.J., Scott, D.R. and Pace, R.W. (2004), “The relationship between organizational commitment and organizational climate in manufacturing”. Human Resource Development Quarterly, Vol. 15 No. 4, pp. 473-488. doi: $10.1002 / \mathrm{hrdq} .1116$

Menezes, I., Zwiegelaar, J., Moraes, E., Mendy, J. and Pires, P. (2019), “Applying network analysis to measure organizational behaviors using R software" paper presented at European Academy of Management (EURAM), 26 June - 30 June, Lisbon, Portugal. Available at: http://www.euram-online.org/programme2019/conferenceprogramme.html

Moran, E.T. and Volkwein, J.F. (1992), "The cultural approach to the formation of organizational climate”. Human Relations, Vol. 45 No. 1, pp. 19-47. doi: $10.1177 \% 2 \mathrm{~F} 001872679204500102$

Morrow, P.C. (1983), “Concept redundancy in organizational research: The case of work commitment”. Academy of Management Review, Vol. 8 No. 3, pp. 486-500. doi: 10.5465/amr.1983.4284606

Mowday, R.T., Steers, R.M. and Porter, L.W. (1979), “The measurement of organizational commitment". Journal of Vocational Behavior, Vol. 14 No. 2, pp. 43-77. doi: 10.1016/00018791(79)90072-1

Mulki, J. and Lassk, F.G. (2019), "Joint impact of ethical climate and external work locus of control on job meaningfulness”. Journal of Business Research, Vol. 99, pp. 46-56. doi: 10.1016/j.jbusres.2019.02.007

Muraki, E. and Carlson, J.E. (1995), “Full-Information Factor Analysis for Polytomous Item Responses”. Applied Psychological Measurement, Vol. 19 No. 1, pp. 73-90. doi: 


\section{$10.1177 / 014662169501900109$}

Newman, M.E.J. (2010), Networks: An introduction. Oxford University Press.

O'Reilly, C.A. and Chatman, J. (1986), “Organizational commitment and psychological attachment: The effects of compliance, identification, and internalization on prosocial behaviour". Journal of Applied Psychology, Vol. 71 No. 3, pp. 492. doi: $10.1037 / 0021-9010.71 .3 .492$

Opsahl, T., Agneessens, F. and Skvoretz, J. (2010), "Node centrality in weighted networks: Generalizing degree and shortest paths". Social Networks, Vol. 32 No. 3, pp. 245-251. doi: $10.1016 /$ j.socnet.2010.03.006

Patterson, M.G., West, M.A., Shackleton, V.J., Dawson, J.F., Lawthom, R., Maitlis, S., Robinson, D.L. and Wallace, A.M. (2005), "Validating the organizational climate measure: Links to managerial practices, productivity and innovation". Journal of Organizational Behavior, Vol. 26 No. 4, pp. 379-408. doi: 10.1002/job.312

Pons P. and Latapy M. (2005), “Computing communities in large networks using random walks”. Yolum, P., Güngör T., Gürgen F., Özturan C. (Eds.) ISCIS 2005: Computer and Information Sciences. Lecture Notes in Computer Science, Vol. 3733, pp. 284293. Springer, Berlin, Heidelberg. doi: 10.1007/11569596_31

Porath, C., Spreitzer, G., Gibson, C. and Garnett, F.G. (2012), “Thriving at work: Toward its measurement, construct validation, and theoretical refinement". Journal of Organizational Behavior, Vol. 33 No. 2, pp. 250-275. doi: 10.1002/job.756

Riketta, M. (2005), “Organizational identification: A meta-analysis”. Journal of Vocational Behavior, Vol. 66 No. 2, pp. 358-384. doi: 10.1016/j.jvb.2004.05.005

Robinaugh, D.J., Millner, A.J. and McNally, R.J. (2016), “Identifying highly influential nodes in the complicated grief network". Journal of Abnormal Psychology, Vol. 125 No. 6, pp. 747-757. doi: 10.1037/abn0000181 
Schneider, B., Ehrhart, M.G. and Macey, W.H. (2011), "Perspectives on organizational climate and culture", S. Zedeck (Ed.), APA Handbook of Industrial and Organizational Psychology, Vol 1: Building and developing the organization, American Psychological Association, Washington, DC, pp. 373-414. doi: $10.1037 / 12169-012$

Soane, E., Truss, C., Alfes, K., Shantz, A., Rees, C. and Gatenby, M. (2012), “Development and application of a new measure of employee engagement: the ISA Engagement Scale”. Human Resource Development International, Vol. 15 No. 5, pp. 529-547. doi: $10.1080 / 13678868.2012 .726542$

Spreitzer, G., Sutcliffe, K., Dutton, J., Sonenshein, S. and Grant, A.M. (2005), “A socially embedded model of thriving at work". Organization Science, Vol. 16 No. 5, pp. 537549. doi: $10.1287 /$ orsc. 1050.0153

Tustin, C.M. (1993), "A consensus approach to the measurement of organisational climate". Journal of Industrial Psychology, Vol. 19 No. 1, pp. 1-4. doi: 10.4102/sajip.v19i1.548

Van Borkulo, C.D., Borsboom, D., Epskamp, S., Blanken, T.F., Boschloo, L., Schoevers, R.A. and Waldorp, L.J. (2014), “A new method for constructing networks from binary data". Scientific Reports, Vol. 4 No. 1, pp. 1-10. doi: 10.1038/srep05918 van Der Maas, H.L.J., Dolan, C.V., Grasman, R.P.P.P., Wicherts, J.M., Huizenga, H.M. and Raijmakers, M.E.J. (2006), “A dynamical model of general intelligence: The positive manifold of intelligence by mutualism". Psychological Review, Vol. 113 No. 4, pp. 842-861. doi: 10.1037/0033-295X.113.4.842

Villamizar Reyes, M.M. and Castañeda Zapata, D.I. (2014), "Relation between organizational climate and its dimensions and knowledge-sharing behavior among knowledge workers". International Journal of Psychological Research, Vol. 7 No. 2 , pp. 64-75. doi: 10.21500/20112084.659 
Walumbwa, F.O., Avolio, B.J., Gardner, W.L., Wernsing, T.S. and Peterson, S.J. (2008), Authentic leadership: Development and validation of a theory-based measure. Journal of management, Vol. 34 No. 1, pp. 89-126. doi: 10.1177\%2F0149206307308913

Wild, W. (2019), Exploring the lived experiences of owner-managers who thrive at work. Doctoral dissertation. University of Chester, UK, available at https://chesterrep.openrepository.com/handle/10034/622940

Wirth, R.J. and Edwards, M.C. (2007), "Item factor analysis: Current approaches and future directions". Psychological Methods, Vol. 12 No. 1, pp. 58-79. doi: 10.1037/1082989X.12.1.58

Worley, C. G., Williams, T. D., \& Lawler III, E. E. (2014). The agility factor: Building adaptable organizations for superior performance. John Wiley \& Sons.

Yang, Z., Algesheimer, R. and Tessone, C.J. (2016), “A Comparative Analysis of Community Detection Algorithms on Artificial Networks". Scientific Reports, Vol. 6 No. 1, pp. 30750. doi: 10.1038/srep30750 
Table 1.

Dimensions of organizational climate investigated in the current study

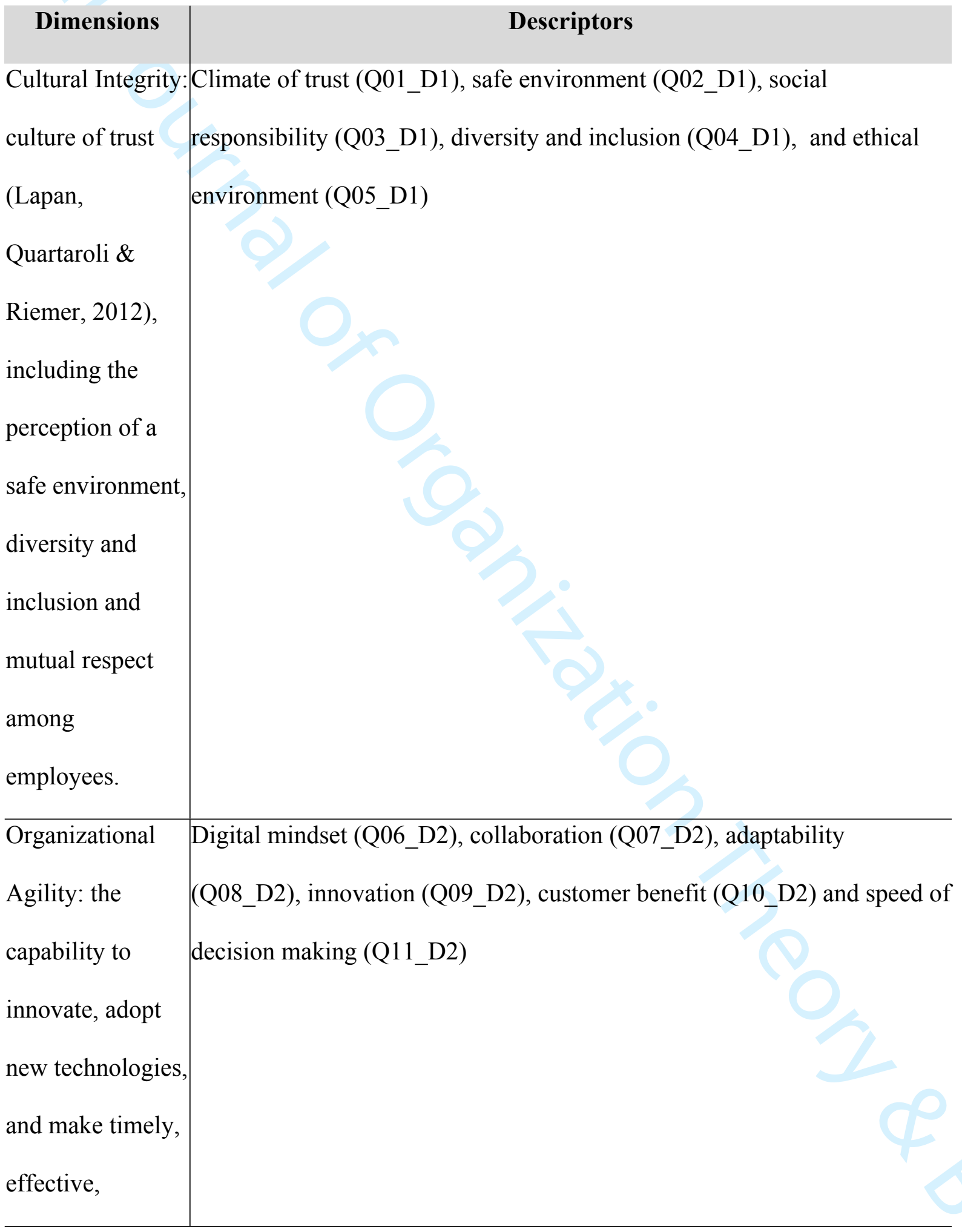


sustained

organizational

change (Worley,

Williams \&

Lawler III, 2014).

Responsible $\quad$ Coaching (Q12_D3), listening (Q13_D3), respect and dignity (Q14_D3),

Leadership: decision making (Q15_D3), upward feedback (Q16_D3) and balanced

social-relational objectives (Q17_D3)

and ethical

phenomenon,

which occurs in

social processes

of interaction

(Maak \& Pless,

2006).

Healthy Work $\quad$ Flexibility (Q18_D4), psychological safety (Q19_D4), balance (Q20_D4),

Environment: belonging (Q21_D4) and health and wellness (Q22_D4)

health promotion,

wellbeing at work

and psychological

safety.

\begin{tabular}{l|l}
\hline Equitable & Fair pay/equity (Q23_D5), competitive package (Q24_D5), performance
\end{tabular}

Rewards: $\quad$ management (Q25_D5), reward for performance (Q63_D5), exceeding

Extrinsic rewards expectations (Q27_D5) and financial wellbeing (Q28_D5)

that drive 
employee morale

(Datta, 2012).

\begin{tabular}{l|l}
\hline Compelling & Career paths (Q29_D6), learning (Q30_D6), meaningful work (Q31_D6), \\
Careers: career & career goals (Q32_D6), personalized careers (Q33_D6) and fair \\
paths and & opportunity to advance (Q34_D6)
\end{tabular}

opportunities to

assist employees

in their career

progression.

\begin{tabular}{l|l}
\hline Thriving & Energized (Q35_D7), full potential (Q36_D7), empowered to contribute \\
Individuals: & (Q37 D7), wellness (Q38_D7), whole self (Q39_D7)
\end{tabular}

positive feeling

of having energy

available,

reflecting feelings

of aliveness

(Spreitzer et al, 2005).

Engagement: the Advocacy (Q40_D8), pride (Q41_D8), commitment (Q42_D8) and

employing or motivation (Q43_D8)

expressing of

oneself

physically,

cognitively, and

emotionally 
during work role performances

(Kahn, 1990). 
Table 2.

Inter-scale correlations and internal consistency reliability (Cronbach's alpha coefficients, on the diagonal bold)

\begin{tabular}{|c|c|c|c|c|c|c|c|}
\hline Cultural & Organizational & Responsible & Healthy & Equitable & Compelling & Thriving & Engagement \\
\hline
\end{tabular}

\begin{tabular}{ll}
\hline Cultural & $\mathbf{0 . 7 9}$
\end{tabular}

Integrity

Organization $\quad 0.72 * * *$

$\mathbf{0 . 8 2}$

al Agility

Responsible

$0.71 * * *$

$0.73 * * *$

0.82

Leadership

Healthy

$0.67 * * *$

$0.66^{* * *}$

$0.68 * * *$

0.77

Work

Environment

Equitable

$0.62 * * *$

$0.63^{* * *}$

$0.67 * * *$

$0.68 * * *$

0.89

Rewards 


$\begin{array}{lllllll}\text { Compelling } & 0.65^{* * *} & 0.66^{* * *} & 0.68^{* * *} & 0.69 * * * & 0.78^{* * *} & \mathbf{0 . 9 1} \\ \text { Careers } & & & & & \\ \text { Thriving } & 0.67 * * * & 0.65^{* * *} & 0.67 * * * & 0.72 * * * & 0.69 * * * & 0.80^{* * *}\end{array}$

Individuals

$\begin{array}{lllllllll}\text { Engagement } & 0.64 * * * & 0.62 * * * & 0.62 * * * & 0.66^{* * *} & 0.66^{* * *} & 0.73^{* * *} & 0.76^{* * *} & \mathbf{0 . 8 6}\end{array}$

Note: ${ }^{*} \mathrm{p}<.05 . * * \mathrm{p}<.01 . * * * \mathrm{p}<.001$ 
Table 3.

Psychometric properties for the organizational climate instrument

\begin{tabular}{|c|c|c|c|c|c|c|c|}
\hline & Item & Loadings & $\mathbf{a}$ & ritc & Alpha & $\overline{\mathbf{X}}$ & SD \\
\hline \multirow[t]{5}{*}{ Cultural Integrity } & Q01_D1 & 0.78 & 2.11 & 0.60 & 0.74 & 4.08 & 0.92 \\
\hline & Q02_D1 & 0.71 & 1.70 & 0.53 & 0.77 & 4.15 & 0.99 \\
\hline & Q03_D1 & 0.77 & 2.03 & 0.58 & 0.75 & 4.22 & 0.81 \\
\hline & Q04_D1 & 0.76 & 2.00 & 0.59 & 0.75 & 4.00 & 0.93 \\
\hline & Q05_D1 & 0.73 & 1.84 & 0.57 & 0.75 & 4.15 & 0.90 \\
\hline \multirow[t]{6}{*}{ Organizational Agility } & Q06_D2 & 0.72 & 1.77 & 0.56 & 0.80 & 4.21 & 0.88 \\
\hline & Q07_D2 & 0.70 & 1.68 & 0.54 & 0.80 & 4.17 & 0.82 \\
\hline & Q08_D2 & 0.81 & 2.31 & 0.64 & 0.78 & 4.18 & 0.81 \\
\hline & Q09 D2 & 0.84 & 2.67 & 0.68 & 0.77 & 4.16 & 0.87 \\
\hline & Q10_D2 & 0.76 & 1.99 & 0.59 & 0.79 & 4.24 & 0.81 \\
\hline & Q11_D2 & 0.68 & 1.57 & 0.55 & 0.81 & 3.61 & 1.09 \\
\hline \multirow[t]{6}{*}{ Responsible Leadership } & Q12_D3 & 0.86 & 2.86 & 0.64 & 0.78 & 4.01 & 1.05 \\
\hline & Q13_D3 & 0.90 & 3.46 & 0.66 & 0.78 & 4.11 & 0.95 \\
\hline & Q14_D3 & 0.85 & 2.76 & 0.59 & 0.80 & 4.39 & 0.76 \\
\hline & Q15_D3 & 0.64 & 1.41 & 0.58 & 0.80 & 4.12 & 0.92 \\
\hline & O16 D3 & 0.58 & 1.21 & 0.53 & 0.81 & 3.86 & 1.10 \\
\hline & Q17 D3 & 0.62 & 1.33 & 0.55 & 0.80 & 3.94 & 0.97 \\
\hline \multirow[t]{4}{*}{ Healthy Work Environment } & Q18_D4 & 0.56 & 1.14 & 0.48 & 0.78 & 3.61 & 1.40 \\
\hline & Q19 D4 & 0.70 & 1.68 & 0.58 & 0.72 & 3.55 & 1.17 \\
\hline & Q20_D4 & 0.81 & 2.32 & 0.59 & 0.72 & 4.02 & 0.91 \\
\hline & Q21_D4 & 0.82 & 2.39 & 0.58 & 0.73 & 4.34 & 0.77 \\
\hline
\end{tabular}




\begin{tabular}{|c|c|c|c|c|c|c|c|}
\hline & Q22_D4 & 0.81 & 2.37 & 0.61 & 0.71 & 4.05 & 0.96 \\
\hline \multirow[t]{6}{*}{ Equitable Rewards } & Q23_D5 & 0.82 & 2.44 & 0.72 & 0.87 & 3.56 & 1.19 \\
\hline & Q24_D5 & 0.77 & 2.05 & 0.67 & 0.88 & 3.83 & 1.09 \\
\hline & Q25_D5 & 0.84 & 2.67 & 0.71 & 0.87 & 3.78 & 1.06 \\
\hline & Q26_D5 & 0.84 & 2.60 & 0.72 & 0.87 & 3.62 & 1.22 \\
\hline & Q27_D5 & 0.88 & 3.09 & 0.75 & 0.86 & 3.77 & 1.09 \\
\hline & Q28_D5 & 0.80 & 2.29 & 0.68 & 0.87 & 4.00 & 0.96 \\
\hline \multirow[t]{6}{*}{ Compelling Careers } & Q29_D6 & 0.83 & 2.57 & 0.71 & 0.90 & 3.94 & 1.00 \\
\hline & Q30_D6 & 0.87 & 2.95 & 0.75 & 0.89 & 3.98 & 0.99 \\
\hline & Q31_D6 & 0.80 & 2.30 & 0.67 & 0.90 & 4.04 & 0.92 \\
\hline & Q32_D6 & 0.90 & 3.55 & 0.80 & 0.88 & 3.94 & 1.03 \\
\hline & Q33_D6 & 0.91 & 3.61 & 0.80 & 0.88 & 3.90 & 0.99 \\
\hline & Q34_D6 & 0.85 & 2.72 & 0.74 & 0.89 & 3.93 & 1.02 \\
\hline \multirow[t]{5}{*}{ Thriving Individuals } & Q35_D7 & 0.87 & 3.06 & 0.72 & 0.79 & 3.97 & 0.95 \\
\hline & Q36_D7 & 0.85 & 2.75 & 0.69 & 0.80 & 4.02 & 0.99 \\
\hline & Q37_D7 & 0.89 & 3.30 & 0.73 & 0.79 & 4.05 & 0.87 \\
\hline & Q38_D7 & 0.70 & 1.68 & 0.54 & 0.84 & 4.12 & 0.80 \\
\hline & Q39_D7 & 0.73 & 1.80 & 0.58 & 0.83 & 4.11 & 0.86 \\
\hline \multirow[t]{4}{*}{ Engagement } & Q40_D8 & 0.92 & 3.91 & 0.75 & 0.82 & 4.43 & 0.74 \\
\hline & Q41_D8 & 0.95 & 4.97 & 0.78 & 0.81 & 4.45 & 0.73 \\
\hline & Q42_D8 & 0.80 & 2.24 & 0.68 & 0.85 & 4.22 & 0.96 \\
\hline & Q43_D8 & 0.82 & 2.43 & 0.69 & 0.84 & 4.24 & 0.86 \\
\hline
\end{tabular}

Note: Loadings - Factor loadings; a = IRT discrimination parameter; ritc: corrected item-total correlation; Alpha $=$ Cronbach's alpha if item deleted. 
Figure 1.

Organizational climate network estimated for the training dataset.

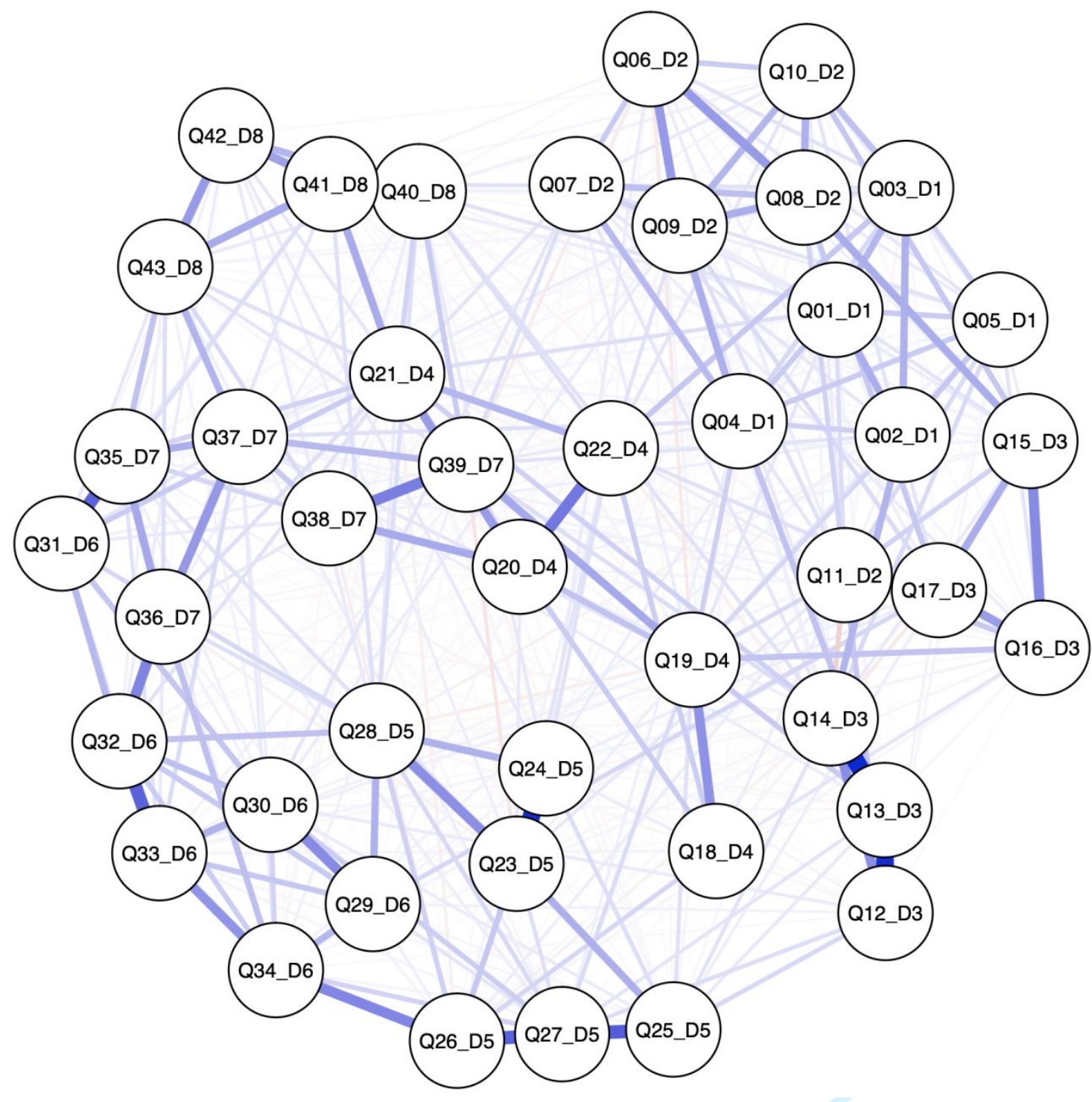

\begin{tabular}{|l|}
\hline Q01 D1: climate of trust \\
Q02 D1: safe environment \\
\hline Q03 D1: social responsibility \\
Q04_D1: diversity and inclusion \\
Q05_D1: ethical environment \\
\hline Q06_D2: digital mindset \\
Q07_D2: collaboration \\
Q08 D2: adaptability \\
Q09_D2: innovation \\
Q10D2: customer benefit \\
Q11 D2: speed of decision making \\
\hline Q12_D3: coaching \\
Q13_D3: listening \\
Q14_D3: respect and dignity \\
Q15_D3: decision making \\
Q16_D3: upward feedback \\
Q17_D3: balanced objectives \\
\hline
\end{tabular}

\begin{tabular}{|l|}
\hline Q18 D4: flexibility \\
Q19 D4: psychological safety \\
\hline Q20 D4: balance \\
Q21_D4: belonging \\
Q22_D4: health and wellness \\
\hline Q23_D5: fair pay/equity \\
\hline Q24 D5: competitive package \\
\hline Q25 D5: performance \\
\hline management \\
\hline Q63 D5: reward for performance \\
Q27 D5: exceeding expectations \\
\hline Q29 D5: financial wellbeing \\
\hline Q30_D6: learning \\
Q31_D6: meaningful work \\
Q32_D6: career goals \\
Q33_D6: personalized careers \\
Q34 D6: fair opportunity to \\
advance
\end{tabular}

Q37 D7: empowered to contribute Q38_D7:wellness Q39 D7: whole self

Q40 D8: advocacy

Q41 D8: pride

Q42 D8: comitment Q43 D8: motivation 
Figure 2.

Organizational climate network estimated for the testing dataset.

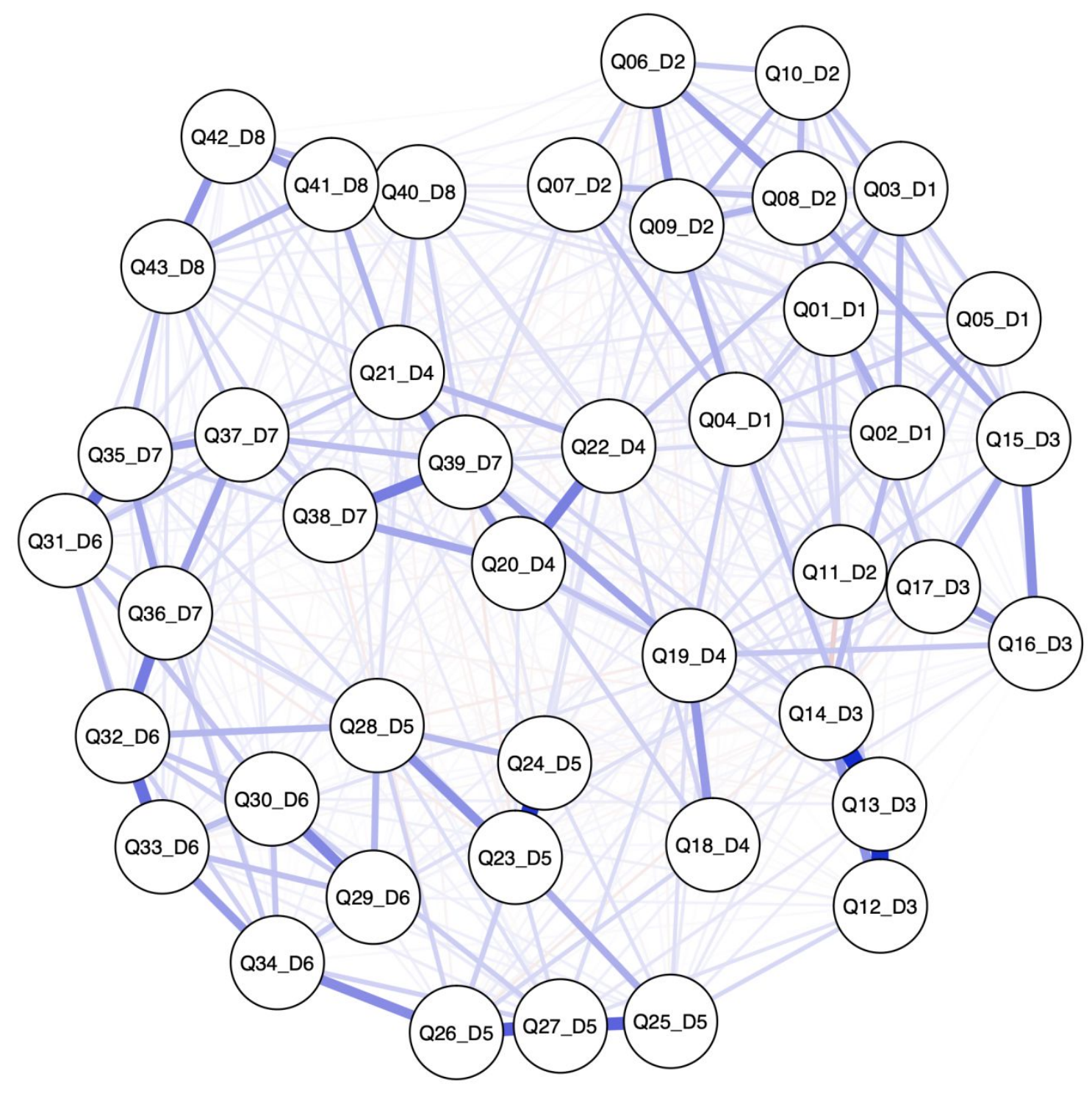


Q06 D2: digital mindset

Q07 D2: collaboration

Q08 D2: adaptability

Q09 D2: innovation

Q10 D2: customer benefit

Q11 D2: speed of decision making

Q12 D3: coaching

Q13 D3: listening

Q14 D3: respect and dignity

Q15 D3: decision making

Q16 D3: upward feedback

Q17 D3: balanced objectives

\begin{tabular}{|l|}
\hline Q18 D4: flexibility \\
Q19 D4: psychological safety \\
Q20 D4: balance \\
Q21 D4: belonging \\
Q22 D4: health and wellness \\
\hline Q23_D5: fair pay/equity \\
Q24_D5: competitive package \\
Q25_D5: performance \\
management \\
Q63_D5: reward for performance \\
Q27_D5: exceeding expectations \\
Q28 D5: financial wellbeing \\
\hline Q29 D6: career paths \\
Q30 D6: learning \\
Q31_D6: meaningful work \\
Q32_D6: career goals \\
Q33_D6: personalized careers \\
Q34_D6: fair opportunity to \\
advance \\
\hline
\end{tabular}

Q35 D7: energized

Q36 D7: full potential

Q37 D7: empowered to contribute

Q38 D7:wellness

Q39 D7: whole self

Q40_D8: advocacy

Q41 D8: pride

Q42 D8: comitment

Q43 D8: motivation

Figure 3.

Organizational climate network estimated for the complete dataset. 


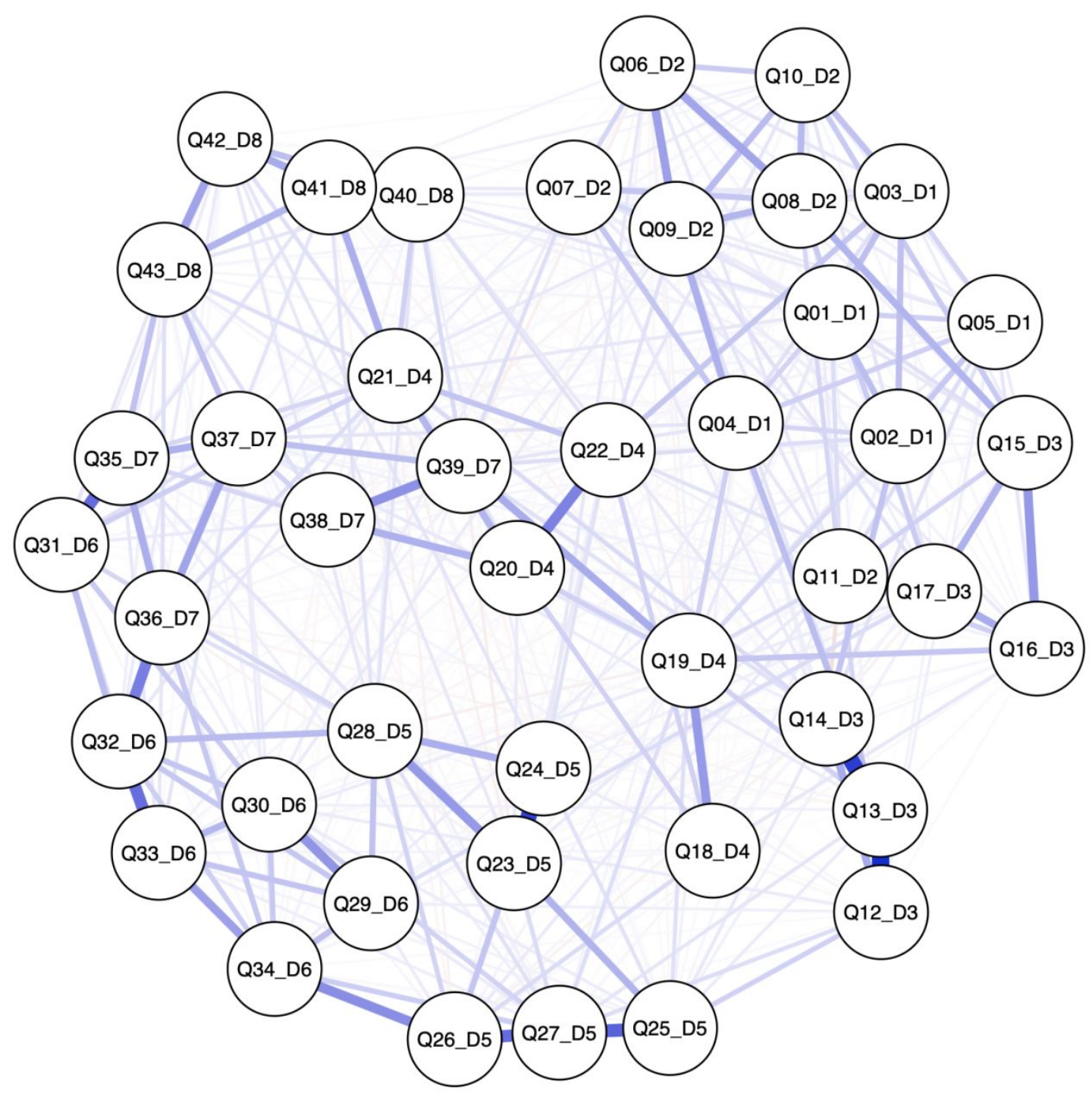

\begin{tabular}{|l|}
\hline Q01 D1: climate of trust \\
Q02 D1: safe environment \\
Q03 D1: social responsibility \\
Q04 D1: diversity and inclusion \\
Q05 D1: ethical environment \\
\hline Q06_D2: digital mindset \\
Q07_D2: collaboration \\
Q08_D2: adaptability \\
Q09_D2: innovation \\
Q10_D2: customer benefit \\
Q11_D2: speed of decision making \\
\hline Q12 D3: coaching \\
\hline Q13 D3: listening \\
\hline Q14 D3: respect and dignity \\
\hline Q15 D3: decision making \\
Q16 D3: upward feedback \\
Q17_D3: balanced objectives \\
\hline
\end{tabular}

\begin{tabular}{|l|}
\hline Q18 D4: flexibility \\
Q19D4: psychological safety \\
Q20 D4: balance \\
Q21 D4: belonging \\
Q22 D4: health and wellness \\
\hline Q23_D5: fair pay/equity \\
Q24_D5: competitive package \\
Q25_D5: performance \\
management \\
Q63_D5: reward for performance \\
Q27D5: exceeding expectations \\
Q28D5: financial wellbeing \\
\hline Q29D6: career paths \\
Q30D6: learning \\
Q31 D6: meaningful work \\
Q32 D6: career goals \\
Q33 D6: personalized careers \\
Q34_D6: fair opportunity to \\
advance
\end{tabular}

\begin{tabular}{|l|}
\hline Q35 D7: energized \\
Q36 D7: full potential \\
\hline Q37 D7: empowered to contribute \\
\hline Q38 D7:wellness \\
Q39 D7: whole self \\
\hline Q40_D8: advocacy \\
Q41_D8: pride \\
Q42_D8: comitment \\
Q43 D8: motivation \\
\hline
\end{tabular}


Figure 4.

Expected Influence of the items in the organizational climate network for both training and testing datasets. 


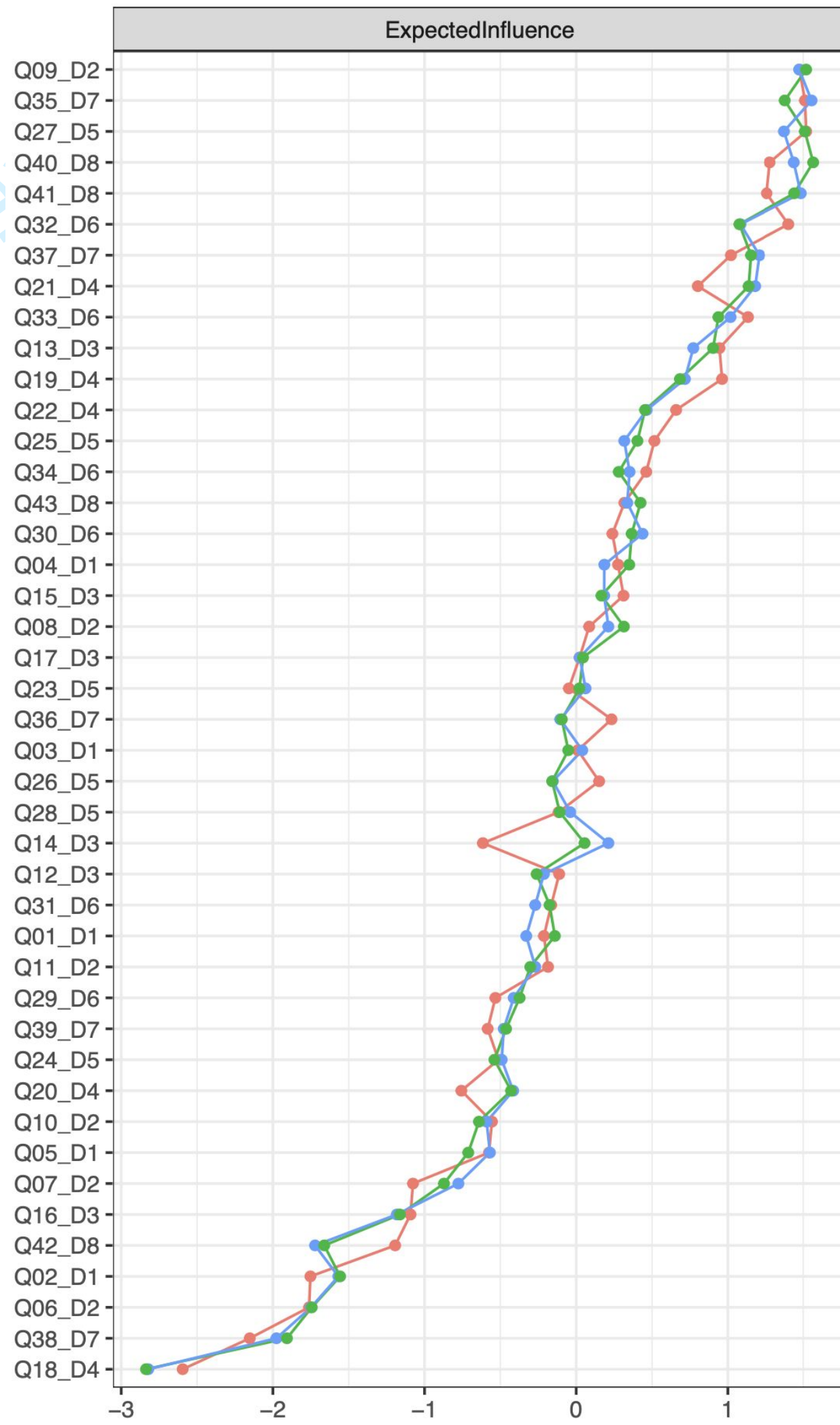

type

$\rightarrow$ Complete

$\multimap$ Testing

$\rightarrow$ Training

Figure 5. 
Network community detected for training, testing and complete datasets.

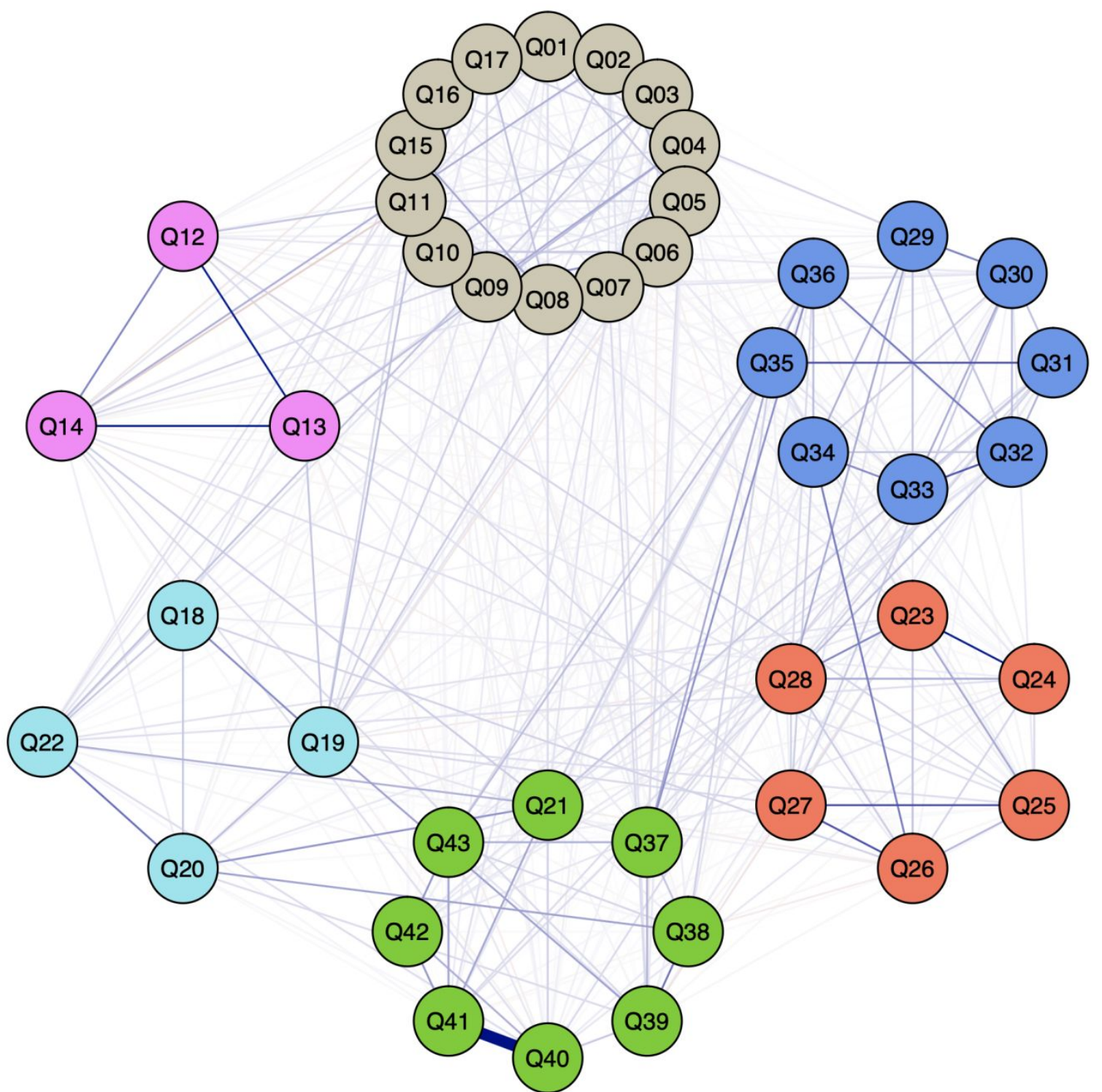

Q01: climate of trust

Q02: safe environment

Q03: social responsibility

Q04: diversity and inclusion

Q05: ethical environment

Q06: digital mindset

Q07: collaboration

Q08: adaptability

Q09: innovation

Q10: customer benefit

Q11: speed of decision making

Q12: coaching

Q13: listening

Q14: respect and dignity

Q15: decision making

Q16: upward feedback

Q17: balanced objectives

\begin{tabular}{|l|}
\hline Q18: flexibility \\
Q19: psychological safety \\
Q20: balance \\
Q21: belonging \\
Q22: health and wellness \\
\hline Q23: fair pay/equity \\
Q24: competitive package \\
Q25: performance management \\
Q63: reward for performance \\
Q27: exceeding expectations \\
Q28: financial wellbeing \\
\hline Q29: career paths \\
Q30: learning \\
Q31: meaningful work \\
Q32: career goals \\
Q33: personalized careers \\
Q34: fair opportunity to advance \\
\hline
\end{tabular}

Q35: energized

Q36: full potential

Q37: empowered to contribute

Q38:wellness

Q39: whole self

Q40: advocacy

Q41: pride

Q42: comitment

Q43: motivation 


\section{Measuring organizational climate via psychological networks analysis}

\section{Supplementary materials}

This section intends to provide an introduction to psychological networks and make available the R syntax used for the data analyses carried out in this study.

\section{A network approach to organizational behavior}

The amount of research investigating psychological networks has substantially grown over the last decade, despite mainly being applied to the fields of psychiatry, clinical psychology and personality. Psychological networks are mutually reinforcing elements connected by associations (Marsman et al., 2018; van der Maas et al., 2006) to better explain how complex interactions among different psychological variables occur (Epskamp et al., 2018). As psychological networks do not model the dependencies among the observable variables (Borsboom, 2008), their design differs from latent causal models, such as unidimensional item response theory and structural equation modelling. Based on a common cause framework, while latent causal models investigate organizational climate by analyzing each dimension separately, psychological networks explore the interactions between them as a complex system.

A psychological network comprises two essential elements: nodes, represented by observable variables or test items, and edges, the associations formed among them. From a statistical perspective, whereas nodes are the main effects, edges are the pairwise interactions (Marsman et al., 2018). When applied to research in organizational behavior, psychological networks not only explore how different variables influence one another, but are also able to underline which ones are the most central for explaining the construct under investigation. 
Although the majority of the studies employing psychological networks follow a nonexperimental design, potential causal structures in a pathway may be identified. For instance, workers might not rely on their leaders, which can, in turn, affect their organizational commitment and therefore reduce the team performance. This causal structure indicates that we could predict team performance by knowing the attitudes towards the leadership that could lead a worker to demonstrate a poor performance with their group. However, we can also predict team performance from organizational commitment, making the knowledge on the attitudes towards leadership no longer necessary to predict team performance. As a result, the correlation estimated between leadership and team performance is tested to be zero, making these two variables conditionally independent of each other. This property will be generalized to all edges of a network, which will be calculated using partial correlation coefficients when data is assumed to be continuous or ordinal. Partial correlation networks are a subclass of undirected networks called Markov random fields in which edges connect nodes by solid lines with no arrows, showing that the edge $(\mathrm{x}, \mathrm{y})$ is identical to the edge $(y, x)$.

To illustrate an application of network analysis to a study in organizational behavior, we selected a data set comprised of 238 workers who responded to eleven items. Seven items were chosen from the ISA Engagement Scale (Soane et al., 2012), and four items measuring the transparency dimension were selected from the Authentic Leadership Questionnaire (Walumbwa et al., 2008). The items are listed in Table 1.

\section{[Insert Table 1 Here]}

Figure 1 shows the graphical representation of a psychological network with the eleven items listed in Table 2. The thickness of the edges represents the strengh of the 
association between two nodes, controlled for by all other variables through partial correlation (Epskamp et al., 2018). The thicker an edge (solid line) is, the strongest the association between two nodes (circles). Blue edges represent positive associations, whereas red edges amount to negative associations.

The network visualization shows that feeling positive about the work (ENG01) is strongly related to sharing the same work values as other colleagues (ENG02), which in turn can motivate leaders to seek others' opinions before making up their minds (TRANSP03). As such, rather than test a few independent comparisons between the items of these two dimensions via regression models, a psychological network would assume that leadership develops from the complex interaction among all variables under measurement. It follows that the more variables a construct has, the greater the chance of identifying significant relations among them, making the application of psychological networks to the investigation of organizational climate an important methodological advance.

\section{[Insert Figure 1 Here]}

The last step involved in the estimation of psychological networks concerns the predictability of the nodes, or rather how influential they are in a network. This can be assessed via three centrality indices (Constantini et al., 2015; Newman, 2010; Opsahl et al., 2010): a) Strength, which shows how well a node is directly connected to other nodes, b) Closeness, which illustrate how well a node is indirectly connected to other nodes, and c) Betweenness, which quantifies the number of times a node acts as a bridge along the shortest path between two other nodes (Epskamp et al., 2018). Notwithstanding the wide use of these measures in network analysis, their computation does not distinguish between positive and negative edges, rendering them unsuitable for identifying the most relevant nodes in networks 
where both positive and negative associations are crucial to understanding the system of relationships as a whole. In order to address this limitation, Robinaugh et al. (2016) proposed an index called Expected Influence (EI) that accounts for the presence of negative edges. If a network has only positive edges, EI and Strength indices will provide the same results, but in the presence of negative edges, the EI index will be decreased, whereas the Strength will increase by considering the absolute values of all edges.

Figure 2 shows the Expected Influence for the network above relating the items of engagement and leadership transparency. The interpretation is quite straightforward: the highest an index is positioned on the right-hand side, the greater the positive influence of a node, with the leftmost values representing the most negative influential nodes. Centrality measures, including Expected Influence, are shown as standardized z-scores in most of the statistical packages to provide interpretability. As shown in Figure 1, sharing the same work values as other colleagues (ENG02) is the variable most likely to positively influence the network, whereas openly sharing feelings with others (TRANSP4) may negatively impact the network, if not taken into account. For cross-sectional network models using small sample sizes, Epskamp et al. (2017) recommend calculating the stability of centrality indices and the accuracy of edge-weights. However, as this investigation uses a large data set, these estimates would typically produce non-significant differences between the observed and expected values. More information on how to calculate these measures can be found in Menezes et al. (2019).

[Insert Figure 2 Here]

In psychological networks, the magnitude of the relationship between two variables is a parameter estimated from data. One of the most popular techniques for estimating network 
models based on continuous or ordinal data is the Gaussian Graphical Model, a pairwise Markov random field (PMRF) that calculates the partial correlation coefficient for the edges by conditioning on all other variables in the network. In order to enhance the prediction accuracy, interpretability and generalizability, a regularization technique called LASSO (least absolute shrinkage and selection operator) is further adopted, mainly when small samples are used (Epskamp et al., 2017). By using LASSO, the usual sum of squared errors is minimized due to a penalty that bound the total sum of the absolute values of the edges. As a result, some edge estimates are reduced to zero, while only a subset of covariates is selected in the final model. This type of network is called sparse, opposed to a dense network where each node is linked to every node in the network. The final step in the estimation process is to choose a tuning parameter to control the amount of shrinkage and finally perform the model selection. The Extended Bayesian Information Criterion (EBIC; Chen and Chen, 2008), an extension of the Bayes Information Criteria, has been the algorithm used for model selection since it has worked well with the estimation of psychological networks based on polytomous data (GGM) and a large number of covariates.

Psychological networks as a research technique are still in its infancy, but it represents an invaluable tool to gain insights into associations among various organizational variables. Furthermore, it can be used as an exploratory approach to formulate research hypotheses and design confirmatory studies after identifying the most relevant connections observed in a network.

\section{References}

Borsboom, D. (2008), "Psychometric perspectives on diagnostic systems". Journal of Clinical Psychology, Vol. 64 No. 9, pp. 1089-1108. doi: 10.1002/jclp.20503 Chen, J. and Chen, Z. (2008), "Extended Bayesian information criteria for model selection 
with large model spaces". Biometrika, Vol. 95 No. 3, pp. 759-771. doi:

10.1093/biomet/asn034

Constantini, G., Epskamp, S., Borsboom, D., Perugini, M., Mõttus, R., Waldorp, L.J. and Cramer, A.O.J. (2015), "State of the aRt personality research: A tutorial on network analysis of personality data in R". Journal of Research in Personality, Vol. 54, pp. 13-29. doi: 10.1016/j.jrp.2014.07.003

Epskamp, S., Borsboom, D. and Fried, E.I. (2018), "Estimating psychological networks and their accuracy: A tutorial paper”. Behavior Research Methods, Vol. 50 No. 1, pp. $195-$ 212. doi: $10.3758 / \mathrm{s} 13428-017-0862-1$

Epskamp, S., Rhemtulla, M. and Borsboom, D. (2017), “Generalized network psychometrics: combining network and latent variable models". Psychometrika, Vol. 82 No. 4, pp. 904-927. doi: 10.1007/s11336-017-9557-x

Marsman, M., Borsboom, D., Kruis, J., Epskamp, S., van Bork, R., Waldorp, L.J., Maas, H. L.J. van der and Maris, G. (2018), “An Introduction to Network Psychometrics: Relating Ising Network Models to Item Response Theory Models”. Multivariate Behavioral Research, Vol. 53 No. 1, pp. 15-35. doi: 10.1080/00273171.2017.1379379

Menezes, I., Zwiegelaar, J., Moraes, E., Mendy, J. and Pires, P. (2019), “Applying network analysis to measure organizational behaviors using R software" paper presented at European Academy of Management (EURAM), 26 June - 30 June, Lisbon, Portugal. Available at: http://www.euram-online.org/programme2019/conferenceprogramme.html

Newman, M.E.J. (2010), Networks: An introduction. Oxford University Press.

Opsahl, T., Agneessens, F. and Skvoretz, J. (2010), "Node centrality in weighted networks: Generalizing degree and shortest paths". Social Networks, Vol. 32 No. 3, pp. 245-251. doi: 10.1016/j.socnet.2010.03.006 
Robinaugh, D.J., Millner, A.J. and McNally, R.J. (2016), “Identifying highly influential nodes in the complicated grief network". Journal of Abnormal Psychology, Vol. 125 No. 6, pp. 747-757. doi: 10.1037/abn0000181

Soane, E., Truss, C., Alfes, K., Shantz, A., Rees, C. and Gatenby, M. (2012), “Development and application of a new measure of employee engagement: the ISA Engagement Scale”. Human Resource Development International, Vol. 15 No. 5, pp. 529-547. doi: $10.1080 / 13678868.2012 .726542$

van Der Maas, H.L.J., Dolan, C.V., Grasman, R.P.P.P., Wicherts, J.M., Huizenga, H.M. and Raijmakers, M.E.J. (2006), “A dynamical model of general intelligence: The positive manifold of intelligence by mutualism". Psychological Review, Vol. 113 No. 4, pp. 842-861. doi: 10.1037/0033-295X.113.4.842

Walumbwa, F.O., Avolio, B.J., Gardner, W.L., Wernsing, T.S. and Peterson, S.J. (2008), Authentic leadership: Development and validation of a theory-based measure. Journal of management, Vol. 34 No. 1, pp. 89-126. doi: 10.1177\%2F0149206307308913 
Table 1.

Items of ISA Engagement Scale and Authentic Leadership Questionnaire's transparency dimension.

\begin{tabular}{ll}
\hline ISA Engagement Scale & $\begin{array}{l}\text { Authentic Leadership Questionnaire } \\
\text { (Transparency dimension) }\end{array}$ \\
\hline ENG01 - I feel positive about my work. & $\begin{array}{l}\text { TRANSP1 - I let others know who I truly } \\
\text { am as a person. }\end{array}$ \\
$\begin{array}{l}\text { ENG02- I share the same work values as my } \\
\text { colleagues. }\end{array}$ & $\begin{array}{l}\text { TRANSP2 - I admit my mistakes to others. } \\
\text { TRANSP3- I seek others' opinions before } \\
\text { making up my own mind. }\end{array}$ \\
ENG03- I concentrate on my work. & $\begin{array}{l}\text { TRANSP4 - I openly share my feelings with } \\
\text { others }\end{array}$ \\
ENG04 - I pay a lot of attention to my work. & \\
$\begin{array}{l}\text { ENG05 - I share the same work goals as my } \\
\text { colleagues. } \\
\text { ENG06 - I focus hard on my work. }\end{array}$ & \\
ENG07 - I feel energetic in my work. &
\end{tabular}


Figure 1.

A graphical representation of a psychological network showing relations among items measuring engagement and transparency.

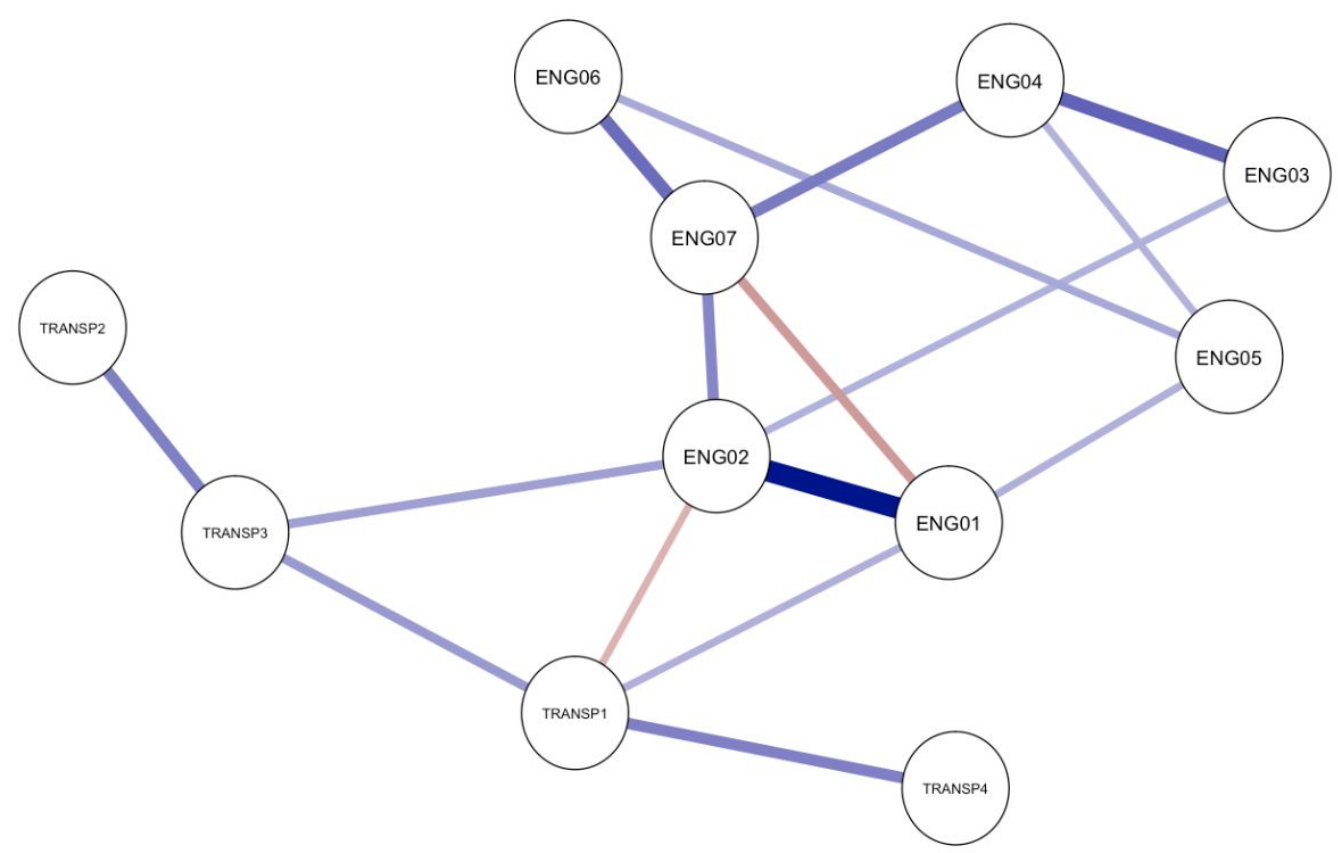


Figure 2.

Expected Influence of the items measuring engagement and transparency based on the estimation of a psychological network.

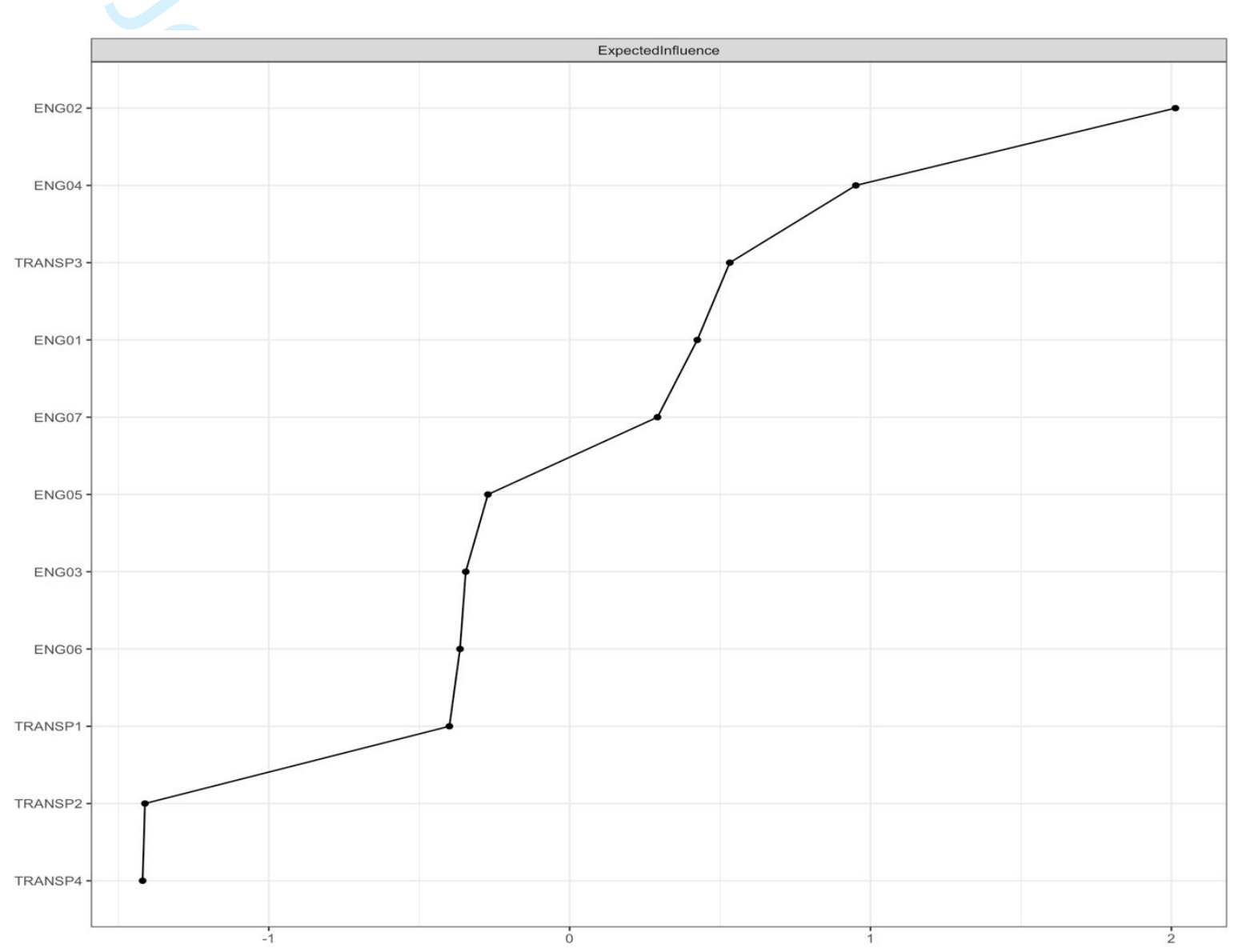

